each subsequent year it has fallen at an accelerating rate. By 1965 there were 750 fewer general practitioners than in 1960, nearly all of the fall occurring after 1962. In the early 1950s, on the other hand, the general practitioners were increasing by 300 to 400 per year.

The number of consultants (excluding honorary staff and locumtenents) in England and Wales increased by 1,034 between 1962 and 1965, but this was largely offset by a fall of 933 in the number of senior hospital medical officers in the same period.

In 1960 there were 8,100 junior hospital doctors of registrar grade or below in England and Wales. By 1965 the number had risen by 2,100 , but 1,750 of this increase was due to an increase in doctors born outside the British Isles. Between 1962 and 1965 the number of British-born doctors of junior hospital grades fell by 80 . The increasing dependence of the hospital service upon doctors from overseas is shown by the fact that in 1960 2,890 junior hospital doctors in England and Wales were born outside the British Isles (36\% of the total), but by 1965 the number from overseas had risen to $4,650(46 \%$ of the total).

Large-scale medical emigration has been a significant aspect of British medicine for over 10 years, and is now a major factor contributing to the dwindling supply of fully trained medical manpower in Britain. In 1964 Professor Abel-Smith wrote that the loss by emigration of the equivalent of nearly onequarter of the output of the medical schools " can be regarded as a serious matter." In the year 1965 the rate appears to have risen to one-third of the output of the schools.

\section{REFERENCES}

Abel-Smith, B., and Gales, K. (1964a). British Doctors at Home and Abroad. Codicote Press, Welwyn.

Brit. (1964b). Brit. med. F., 2, 53.

Brit. med. f. Suppl., 1962, 2, 15.

Brit. med. 7., 1964, 2, 1.

Oversea Migration Board (1965). Statistics for 1964, p. 8. H.M.S.O.,

Leale, J. R. (1962). Brit. med. F., 1, 782.

(1964). Ibid., 1, 1173.

Whitfield, A. G. W. (1963). Lancet, 2, 874.

\title{
Organization and Function of an Accident Flying Squad
}

\author{
JOHN COLLINS,* M.B., CH.B., M.R.C.S., L.R.C.P.
}

Brit. med. F., 1966, 2, 578-580

The first principle for dealing with the seriously injured is to commence treatment as soon as possible. This is most important when urgent resuscitation is required, as with the severely shocked patient. The accident flying squad was developed on this basis, but the team should also be capable of dealing with any emergency which requires treatment at the scene of the incident. The team should be equipped to carry out essential surgery, but this should be limited to the minimum necessary, as obviously the place for surgery is under the ideal conditions of the operating theatre. The flying squad should reach the patient as quickly as possible with the necessary surgical aid.

\section{History}

The concept of the flying squad is not a new one. In Germany, when the autobahnen were built the severe type of injury which resulted from high-speed accidents demanded a new organization for their treatment, and mobile operating theatres were developed. At one time a similar scheme was introduced by the Birmingham Accident Hospital. Apparently the main drawbacks to these schemes were the size and relative slowness of the vehicles.

The history of the Derby flying squad dates from 1955. The area served by the Derbyshire Royal Infirmary is both urban and rural, in which there are large industrial and mining concerns as well as agricultural communities. There are also important networks of roads and railways and an airport. Such an area, with a population of almost half a million, has a considerable accident potential. Seriously injured patients may have long distances to travel to the hospital, and it was considered reasonable to organize an accident flying squad based at the hospital, to serve this community. Such a team would be available to

*Senior Casualty Officer, Derbyshire Royal Infirmary. deal with any patient who might be at risk, because of the time delay, before reaching surgical aid. The Derby scheme differs from the experiments in Germany and Birmingham in that it is designed to treat all types of accident cases; in eleven years the accent has been mainly on industrial injuries.

\section{Equipment}

The first problem involved when organizing the flying squad was to equip it adequately. There were no available standards for guidance, and a comprehensive list was prepared to cover all possible eventualities. This list proved to be formidable, as many articles were suggested which might be useful but were not essential. Careful pruning reduced the requirements considerably, and eventually a list which appeared to be reasonably adequate was agreed. The suggested instruments, drugs, anaesthetic equipment, dressings, splints, etc., were assembled together to assess the amount of space they would occupy. This demonstrated that even further reduction was necessary.

By obtaining compressed dressings and miniature equipment, where possible, space was saved. Pneumatic plastic splints were found to be space-saving and light. With experience and use some articles of equipment have been discarded and others have been added. By consultation with other departments, improvements in the equipment are constantly being considered. On the whole simple apparatus has been found to be the best because of the special factors of transport and local conditions. It was found convenient to divide the equipment into two categories : the material which must always be taken and the special items which should be available when circumstances required them. All equipment should be inspected and checked at frequent intervals, the surgical instruments and other such material regularly sterilized, and the drugs renewed and replaced by the pharmacist whenever necessary. 
Certain items of equipment are kept for special types of incidents. The Siebe Gorman air-breathing apparatus is available in the equipment cupboard for use when the team may be called to work in contaminated or dangerous atmospheres, and additional masks are available for the use of patients. This is the type of breathing apparatus used by the fire services. Fluorescent suits for use on main roads and the motorway, as well as helmets and overalls, are available for the protection of the team when required. The Ambu ventilator and the footoperated Ambu sucker, which are contained in a hold-all, are very convenient and compact. The Brook airway is extremely useful, and, as a result of its proved value to the Flying Squad, all Derby Borough Police cars and ambulances are now equipped with it. The Beaver ventilator, which is reasonably small and portable, has been adapted for use at the scene of an accident. As it requires mains voltage, a portable box containing accumulators and a transistorized invertor, from which a 240 -volt $\frac{1}{2}$ ampere supply is obtained for several hours, has been developed.

Apart from these special items, there are reserves of equipment which can be sent to the scene of a major accident such as a train crash so that a casualty-clearing station can be set up. These consist of extra instruments, and materials such as blankets, bowls, and other items.

Portability is a factor to be emphasized. This is particularly important in the Derby area, as the squad has to deal with mining accidents. The equipment has to be carried underground, over long distances and where walking may be difficult. Experience has shown that the containers should be robust and easily carried by one person. Each container has a list of its contents on the outside, and clear instructions are painted on each box.

All equipment is constantly available and it is not used for any other purpose, so that when there is a call for aid there is no confusion in gathering it together. The only substance that has to be taken from stock is plasma.

\section{Transport}

Speed being the essence of the service, the idea of using mobile operating theatres, vans, or ambulances was immediately discarded. A large car was the obvious choice, and arrangements were made to use a taxi should it be required. The first call ever received was to a seriously injured man who had been taken to a distant cottage hospital and was unfit to travel any further by ambulance. The limitations of using a taxi were soon apparent, as. it was difficult to locate a taxi quickly and the driver was hindered by traffic regulations.

The Derby Borough Police were consulted and as a result it was suggested that the flying squad should be conveyed in a police car. This has all the possible advantages, and the equipment has been designed to fit into the boot of the car. The team proceeds all the way in the police car and where possible a second police car supplies escort. The Derby Borough Police have been most cooperative in this matter, and usually a car is at the door of the casualty department in from three to five minutes. Nowadays two cars always attend, and thus more equipment can be carried. The police have organized a system of "clearway" for the squad. As soon as the call is received police mobile teams are directed to man all cross-roads and zebra crossings and to clear traffic. In this way, even during times of heavy traffic congestion, a police car with sirens, loudhailer, and lights can usually pass through the town at speed.

If more help or equipment is required extra police cars are readily made available, and on one occasion when twenty-nine people were injured, some seriously, in a bus crash, five borough police cars were used. The Derby Borough Police Force deserves great credit for their contribution to the service, and indeed without it much of the efficiency would be lacking. The police have produced detailed maps of routes to the chief indus- trial concerns, mines, and other vulnerable areas, and these are always available to drivers.

The return journey can be, by comparison with the outward journey, a much more leisurely affair. Ambulances are obtained from the nearest station, and, although only moderate speeds are necessary, as the patient is then on treatment, the police complete their job by escorting the ambulance back to the hospital.

\section{Staff}

The staff of the flying squad is supplied by the casualty department, with assistance from other departments. A member of the casualty unit, an anaesthetist or another doctor, and a trained nurse comprise the team.

Each person must be familiar with his job and know what equipment is available. The anaesthetist is a useful member of the team because the respiratory tract is often involved, resuscitation may be required, or a trapped patient may require an anaesthetic before he can be released. Immediate availability is essential, and a member of the casualty staff is always on call.

\section{Method of Call}

Any person can request the assistance of the team. In practice this usually means that a doctor, nurse, police officer, fire officer, or ambulance crew has initiated the call. Certain special arrangements have been made with large industrial concerns and the airport for calling the flying squad. The person requesting assistance is connected by telephone to the casualty department and is asked to give the location and the approximate number of casualties. Immediately on receipt of a call the Borough Police are informed and the nearest patrol car is directed to the hospital. A second car is available within minutes, and this car may be used to collect a member of the team who is on call but not in the hospital and take him direct to the scene of the incident if the first car has loaded the other members of the team and equipment from the hospital.

\section{Major Accidents}

In preparation for a major accident or disaster, a scheme has been drawn up indicating the action to be taken to deal with multiple casualties. In this scheme the flying squad plays an important part. Immediately on receipt of a call the flying squad would proceed to the scene of the accident and make a reconnaissance. The surgeon-in-charge would assess the seriousness of the incident and report back to the hospital by radio. Further assistance and equipment could be requested and a clearing station established, if necessary. In the hospital a plan for the evacuation of beds has been arranged whereby the less seriously ill patients would be transferred to other hospitals to make room for the admission of casualties, who would be received by a team stationed in the outpatient department.

This scheme for major accidents has been published in the hospital and circulated to all senior staff, wards and departments, and to all other staff involved, including administrative and clerical personnel.

\section{Communication}

In order to have a direct link with the hospital a multichannel radio transmitter/receiver was installed in the casualty department. By a turn of the switch the different ambulance services which serve the Derbyshire Royal Infirmary can be 
reached. That was the first radio of this type to be installed in a hospital in Great Britain, and the flying squad requirements were responsible for its introduction. It is possible, by using this apparatus, for the team at the scene of an accident to talk directly to the staff in the casualty department, and by this means any possible errors or misinterpretation of messages which are relayed by an ambulance controller are avoided. It is also possible for arrangements for treatment to be made in advance of the arrival of a patient at the hospital. The radio has been used by ambulance crews to summon assistance to an accident, and advice can also be given to crews at the scene of an incident. The radio proved so successful that a second receiver/transmitter, on a different frequency, was installed so that the Derby Borough Ambulance service was brought into direct contact with the hospital.

\section{Calls}

At first the number of calls on the service were comparatively few, but they have steadily increased over the years. Up to 18 calls per annum are received at present. In January 1966 there were four calls, whereas in February 1966 there were none. With the opening in December 1965 of the extension of the M.1 as far as Kegworth, which is only eight miles away, an increase in serious road accidents had been expected, but so far there has only been one call, to a seriously injured passenger trapped in a lorry.

The calls come from a wide variety of industries; one call was to release a man trapped in a printing press, and he required an anaesthetic before being released. Another patient was trapped by the wheel of a crane on an overhead gantry and his partially severed foot had to be completely amputated to release him. This was thirty feet above ground. Over the years there have been several calls to attend injured miners. The team goes down the pit to the coal-face or to wherever the injured man may be. Occasionally it has been necessary to treat miners who have been injured in machinery underground, and early commencement of intravenous therapy, as well as surgical procedures, have been undertaken. Supervision of transport of the injured to pithead, particularly where spinal injuries are present, can reduce the incidence of damage to the spinal cord. On several occasions there have been a number of patients to deal with; at one bus accident 19, and at another 29 patients were involved. The team has dealt with numerous accidents where people have been trapped in vehicles, and in such cases the patient has often been on plasma while being released. The team has been called to a doctor's surgery to resuscitate an injured man who had been taken there from work. He had been injured by a dumper. Whenever a case of severe burning is notified to the hospital, particularly if from a distance, early resuscitation of the patient has been made possible by meeting the ambulance and starting the treatment immediately.

For smooth operation the team must work in liaison with police, fire, and ambulance services. It has been emphasized to all authorities that, although a call will be answered without question, particularly when life is at stake, everyone requesting help should bear in mind that the departure of the team to an accident deprives the hospital of medical and nursing personnel. By personal contact with responsible people and an explanation of how the team functions, it has been possible to obtain cooperation in the use of the flying squad. It has been noted in the eleven years of its existence that every call has been reasonable and no "false-alarms," even with good intent, have been recorded.

\section{Cost}

The basic equipment for the flying squad comprised surgical instruments, drums, drugs, and dressings, and these were available from stock. The carrying-cases and portable mains electric supply from batteries were made in the hospital workshops. Special items were purchased to improve the service, and examples of the more expensive of these are: Pye radio transmitter/receiver, $£ 200$; Siebe Gorman breathing apparatus, $£ 70$; Ambu resuscitator and sucker, $£ 40$; Beaver mark II respirator, $£ 215$; equipment for testing for radiation hazards, $£ 220$. The police have not made any charge for their services.

\section{Summary}

The flying squad in Derby has been in existence for eleven years.

Essentially the service is resuscitation, but surgery has been performed when necessary.

Speed is of vital importance when proceeding to an accident. The cooperation of the police is desirable and advantageous.

Since its inception the squad has been called to deal with a great variety of accidents.

Calls for the services of the Derby Flying Squad have steadily increased in numbers and the scope of its work has gradually widened.

The success of early treatment of the injured by the flying squad has amply justified the efforts of the team.

In Derby the flying squad has been found to be very useful, and a plea is made that other areas should seriously consider the advisability of forming similar teams. 